\title{
Examining my-side bias during and after reading controversial historical accounts
}

\section{Kalypso lordanou ${ }^{1}$ (D) Panayiota Kendeou ${ }^{2} \cdot$ Michalinos Zembylas $^{3}$}

Received: 15 October 2019 / Accepted: 28 August 2020 / Published online: 4 September 2020

(C) The Author(s) 2020

\begin{abstract}
The present study examines individuals' thinking during and after reading controversial historical accounts and the possible contribution of epistemic beliefs, emotions, and priorknowledge in this context. Young adults $(n=39)$ were asked to read two accounts about a recent war in their country, an own-side account - from a historian of their ethnic group and an other-side account - from a historian from the adversary ethnic group. Participants were asked to think-aloud and report their emotions during reading. After reading, participants were asked to write a summary. Results showed that participants exhibited my-side bias during reading and writing, while there were also interesting individual differences in epistemic beliefs and prior knowledge. Participants with evaluativist epistemic beliefs were less likely to show my-side bias in the writing task. Epistemic beliefs, along with prior knowledge and the emotion of anger, predicted also lowepistemic processing during reading of other-side text. The paper concludes with a discussion of the educational implications in promoting critical thinking about controversial issues in history.
\end{abstract}

Keywords Epistemic beliefs $\cdot$ Reasoning $\cdot$ Emotion $\cdot$ History $\cdot$ My-side bias $\cdot$ Biases $\cdot$ Prior knowledge

Kalypso Iordanou

KIordanou@uclan.ac.uk

Michalinos Zembylas

m.zembylas@ouc.ac.cy

1 University of Central Lancashire - Cyprus, 12 - 14 University Avenue Pyla, 7080 Larnaka, Cyprus

2 Department of Educational Psychology, University of Minnesota, Minneapolis, MN, USA

3 Programme of Educational Studies, Open University of Cyprus, Latsia, Cyprus 


\section{Introduction}

Promoting critical thinkers is perhaps one of the most important goals of education. Democratic societies need citizens who critically evaluate information to make decisions with an open-mind orientation, away from the burden of prejudice and bias (Baron 2019). Engagement in critical evaluation is fundamental not only for decision making but also for learning. Yet, research shows that the majority of individuals do not engage in critical evaluation of information they read, even though they show sufficient text comprehension skills (Diakidoy et al. 2015). Engagement in critical evaluation and reflection, we would claim, involves using the beliefs that one holds about a topic as an object of examination rather than as the filter for interpreting information. In the former, reflection on one's own beliefs involves first a conscious awareness of the beliefs one holds and a dissociation from those beliefs in order to examine them in the light of new evidence - a process which has the potential to lead to belief change (Murphy and Alexander 2016; Iordanou 2016a). In the latter, employment of one's beliefs to interpret new evidence might lead to biases. Using one's beliefs as the criterion for judging what is "true" or "right", precludes any possibility of belief change. There is accumulative evidence showing that individuals are particularly prone to think with their beliefs rather than about their beliefs leading to phenomena such as my-side bias, a term proposed to describe people's tendency to favor egocentric, one-sided thinking rather than thinking considering multiple perspectives (Baron 1995). This phenomenon is even more concerning in light of findings showing that my-side bias is independent of cognitive ability, educational level and age (Stanovich and Stanovich 2010).

In the present work we aim to gain a deeper understanding about the process of engagement in critical evaluation of information that includes my-side bias. We are particularly interested in examining whether and how individuals engage in critical evaluation when they read different accounts about a controversial issue, that is, an issue for which there are strong beliefs in favor of one or another account (Zembylas and Kambani 2012). We focus particularly on the domain of history, for which limited empirical research exists. In particular, the research that exists so far shows that individuals are prone to biases when reading (Putnam et al. 2018; Zaromb et al. 2018) or writing (De La Paz and Felton 2010; Goldberg et al. 2011) about a historical issue. Our interest is to gain insights on how individuals process contradictory historical accounts. In other words, our focus is not merely on whether contradictory historical accounts are processed differently by different (ethnic) groups; rather, we are interested in uncovering the mechanisms with which individuals process such contradictory information. For this purpose, we examined thinking during reading of multiple texts using think aloud protocols and after reading, in a writing task. We also factored in the possible role of epistemic beliefs and prior knowledge. We use the term "prior knowledge" when referencing to the information that individuals have in their possession about a particular topic, irrespective of whether individuals accept this information or not, and we use the term "belief", when referencing to all that one accepts as or wants to be true (Murphy and Mason 2006). Finally, given that historical topics are often emotionally-charged, the role of emotions during reading is also examined.

\section{Cognitive and motivational biases in thinking of controversial issues}

Research on critical evaluation of controversial issues suggests that this kind of critical evaluation may pose serious challenges. Individuals tend to show my-side bias, a favoritism 
towards egocentric, one-cause explanation of an event that is consistent with their views or beliefs (Baron 1995). They view their own subjective interpretation of a situation as the right one, and are more eager to see the effects of biases in others but not in themselves, known as 'bias blind spot' (Pronin et al. 2002). In reading, research shows that individuals' text comprehension is biased by prior beliefs, as it is evident by having a stronger representation of belief consistent information and weaker representation of belief inconsistent information after reading information on a controversial topic, known as the "text-belief consistency effect" (Maier and Richter 2014). In the case of social-scientific controversies, readers' text comprehension is affected by both readers' beliefs and their level of association with the social group that shares or does not share the same beliefs (Maier et al. 2018b). In writing, research shows that when individuals write argumentative essays on a controversial issue they tend to write one-sided arguments, that is, they present only reasons supporting the position that they favoured (Iordanou et al. 2019a; Kuhn et al. 2016). Construction of two-sided arguments, that is, arguments addressing alternative positions, is rare (Kuhn et al. 2008), although it is considered as an evidence of skilled argumentation (Walton 1989).

These egocentric biases in thinking in favor of one's self and own position are independent of individuals' cognitive ability (Stanovich and West 2008) and are stronger when participants have high emotional conviction on the issue. Participants with high emotional investment on a topic rate opposing arguments as weaker than do participants with low emotional investment on the issue, known as the disconfirmation bias (Edwards and Smith 1996), and engage in different cognitive processing (Maier et al. 2018a). For example, research findings show that readers spend longer time reading belief- inconsistent information, probably because a defensive mechanism is triggered and they need time to consider how to counterargue the beliefinconsistent information (Edwards and Smith 1996). Eye tracking data show that readers with strong beliefs although spend more time during initial reading for inconsistent information, noticing the belief inconsistency, they ignore the inconsistent information during information processing (Maier et al. 2018a). Presumably, readers try to protect their beliefs by either ignoring or devaluating belief-inconsistent information. McCrudden and Sparks (2014) found that task instructions - encouraging readers to focus on the merit of both sides of an issue may reduce belief-motivated reasoning to some readers, yet leaving open the question of why some individuals who received the same instructions still exhibit biases in their reasoning during reading. These research findings highlight that our understanding of cognitive and motivational biases in reasoning is far from complete.

In the domain of history, in particular, research shows that students read historical texts as though they convey meaning in a straightforward way, rather than engage in critical examination of what they read as historians do (Wineburg 1991). At the same time, individuals exhibit an ethnocentric bias or narcissism, showing favoritism to their own nation (Putnam et al. 2018; Zaromb et al. 2018). Further, the expression of strong emotions in history is related to biases in historical reasoning, as reflected in bias use of sources and limitations in argumentative dialogue (Goldberg and Schwarz 2016).

\section{Emotions and thinking}

Several theoretical models propose that emotions influence thinking and learning (Barzilai and Chinn 2018; List and Alexander 2017; Muis et al. 2018). Relevant to the present study is the Cognitive Affective Engagement Model (CAEM) of multiple-source use (List and Alexander 2017), which proposes that thinking during reading of multiple texts is affected by both 
individuals' skills but also their affective engagement, involving their interest and attitudes. Engagement in deep-processing, which is connected with what the researchers call 'critical analytic default stance', requires both evaluative skills and affective engagement. According to the CAEM model, strong affective engagement which is the case when students hold strong attitudes about a topic, what the researchers call "affectively engaged default stance", is likely to lead to superficial processing of attitude-consistent information and to ignoring or dismissing of attitude inconsistent information.

Findings on the role of emotions in cognitive processing are mixed (Goldberg and Schwarz 2016). On the one hand, some research findings show that emotions may impede or facilitate cognitive processing depending on the type of emotion. For example, D'Mello et al. (2014) found that participants who experienced the emotion of confusion, which was triggered by presenting participants with contradictions, had better learning gains compared to participants who did not experience confusion. Burbridge et al. (2005) found that participants who discussed emotionally negatively charged topics, had more reference errors in their speech, an increased heart rate, and an impeded performance on the Stroop task - a measure of cognitive control-, than when they discussed positive or neutral topics.

On the other hand, other research findings show that high emotional arousal is not associated with better cognitive processing (e.g. an argument that is stronger); it only enhances the belief that cognitive processing is better (e.g. an argument that is more persuasive), what is termed an 'illusion of argument justification' (Fisher and Keil 2014). Other research findings show that more complex thinking is associated with lesser affect and holding less extreme position on an issue (Kuhn and Iordanou in press). Consistent with this line of research, Mason et al. (2018) found that emotion regulation was related to better integration of information in reading multiple texts on a controversial topic, while high emotional arousal negatively predicted integration of information suggesting that high emotional arousal may impede cognitive processing of complex cognitive tasks.

Research on teaching and learning history, in particular, suggests that emotions play an important role, yet there is an open debate whether and how emotions should be fostered, especially positive ones, or be avoided all together (Goldberg and Schwarz 2016). This research has important implications, not only at the pedagogical level, but also at the social and political level, because fostering particular emotions in schools can be manipulated for political and ideological purposes, especially in conflict-affected societies (Zembylas 2015).

Relevant to the present study, we examine the effect of emotions on cognitive processing of historical accounts by asking participants to read different accounts on an emotionally-charged historical topic and by asking them to report aloud their emotions in the context of a thinkaloud process while reading ("think aloud emotions"). Participants emotions were also assessed using a self-report questionnaire ("questionnaire emotions"1). Besides emotions, we are also interested in the possible role of individuals' epistemic beliefs on cognitive processing.

\section{Epistemic cognition and thinking}

Beliefs about knowledge and knowing influence learning (see Greene et al. 2016) and thinking (Kuhn 1991; Kuhn 2019). Murphy and Alexander (2013) suggested that beliefs about a field

\footnotetext{
"We used the terms "questionnaire emotions" and "think aloud emotions" to differentiate between emotions reported in writing, in the context of filling out a questionnaire, and emotions reported verbally, during reading, when participants were asked to think aloud, respectively.
} 
can potentially have greater consequences on students' learning than ideas about constructs within a field. Epistemic beliefs are particularly important for understanding and learning complex issues, for which there are different - often contradictory exploratory accounts which need to be reconciled (Kuhn 2019). Our knowledge on individuals' epistemic beliefs in the domain of history and how those beliefs might affect cognitive processing is very limited and based mainly on inferences rather than direct empirical evidence (VanSledright and Maggioni 2016). The limited evidence that exists supports a developmental progression of epistemic beliefs, ranging from a view that there is a direct correspondence between a historical account and reality, to a view that historical accounts are constructed by historians and reflect author's bias, to a view that historical accounts can be judged with criteria to determine if accounts can serve as evidence. This progression of views maps well to the developmental stages of Absolutists, Multiplists and Evaluativists proposed by Kuhn et al.'s (2000) theory of epistemic development (VanSledright and Maggioni 2016). In this context, epistemic cognition progresses from the absolutist level, to the multiplist level and then to the evaluativist level (Kuhn et al. 2000). In the absolutist level, the objective dimension of knowing dominates. Knowledge is conceived as an objective, external entity, which is knowable with certainty. In the multiplist level, knowledge is no longer considered an object that is located in the external world, but a product of the human mind which is located in one's self. At the multiplist level, the uncertain and subjective nature of knowledge come to the foreground and dominates one's view of knowledge. At the evaluativist level, a balance is achieved between the objective and subjective dimensions of knowledge. Constructivist epistemic cognition involves the coordination of the subjective and objective dimensions of knowledge. Through evaluation, the position that is better supported by argument and evidence would be declared as the position that has more merits compared to alternative positions (Kuhn et al. 2000).

Epistemic beliefs influence the cognitive strategies that individuals engage in when reading historical accounts, thereby also influencing the conclusions that they draw from historical accounts and ultimately their learning in history. For example, Ioannou and Iordanou (2019) examined the learning strategies that elementary school students employed when reading a historical account. The results of that study showed a relation between students' epistemic beliefs and the learning strategies they employed in history. In particular, students who were profiled as Evaluativists in history engaged in more effective learning strategies and exhibited better text comprehension compared to students who were profiled as Absolutists. Similar results were observed by Iordanou et al. (2019b) who examined how students engaged in epistemic processing, focusing particularly on how they process evidence during reading of a history and a science text. Results showed that participants who exhibited evaluativist epistemic beliefs and high prior knowledge engaged in more high-level epistemic judgments (i.e., evaluations using the epistemic standard of scientific research) than participants who held either multiplist or absolutist epistemic beliefs.

\section{The present study}

Although the aforementioned studies are informative as to the role of emotions and beliefs on multiple text comprehension processing and outcomes, our understanding of how individuals process controversial historical accounts that are of relevance to them and for which they may hold strong beliefs and emotions, remains limited. Understanding these processes and outcomes is important given the abundance of information and misinformation that individuals 
are exposed to in our post-truth era, making individuals more prone to racism, xenophobia and nationalism (Engle 2018).

In the present study, we examined individuals' thinking during and after reading controversial historical accounts, including an account which was consistent with their beliefs, from a historian of their ethnic group - 'own-side account'- and an account which was inconsistent with their beliefs on the issue, from a historian from the adversary group - 'other-side account'. In this context, we also examined the effects of epistemic beliefs and emotions (evoked during reading), while also taking into account individual differences in prior knowledge.

The research questions and hypotheses of the study were the following:

1 To what extent do individuals differentially process own-sided and the other-sided accounts of a controversial topic?

We hypothesized that individuals would exhibit my-side bias when reading the two historical accounts (Stanovich and West 2008).

2. To what extent do epistemic beliefs, prior knowledge and emotions predict thinking cognitive processing - when reading historical accounts of a controversial topic?

We hypothesized that individuals who hold strong emotions, especially negative ones, would engage in superficial cognitive processing (Burbridge et al. 2005; List and Alexander 2017). Regarding the role of epistemic beliefs, we hypothesized that individuals with mature epistemic beliefs would exhibit less bias during reading of the historical texts (Kuhn 2001, 2019; Iordanou 2016b). Finally, regarding the role of prior knowledge, we hypothesized that individuals with high prior knowledge would exhibit cognitive processing of better quality (Iordanou et al. 2019b).

3. Is there a relationship between epistemic beliefs and my-side bias, as this was reflected in individuals' ability to construct a two-sided report about controversial historical accounts?

We hypothesized that individuals with mature epistemic beliefs would exhibit less bias during writing a report about the texts (Kuhn 2001, Kuhn 2019; Iordanou 2016b).

The context of the present investigation is Cyprus, an ethnically divided society. Participants read about a fundamental historical event that happened in 1974, and led to the ongoing ethnic division of their country. In particular, participants were GreekCypriots who read an account from a historian from their ethnic group, a GreekCypriot historian, as well as an account from a historian from the adversary ethnic group, a Turkish-Cypriot historian. Previous research has shown that within each community there are strongly held narratives about what happened in 1974; for example, the Greek-Cypriots talk about the 'Turkish invasion of 1974' whereas Turkish-Cypriots call it a 'peace operation' (Papadakis 2008). Previous research has also shown that this historical event is an emotionally-charged and controversial issue for Cyprus, that is, participants within each ethnic community hold strong beliefs and emotions in favor of one or another side of the story (Zembylas et al. 2016; Zembylas and Kambani 2012). 


\section{Method}

\section{Participants}

Thirty-nine young adults $\left(M_{\mathrm{Age}}=24.22, S D=9.27\right)$ participated in individual interviews. All participants were from the same ethnic group, Greek-Cypriots, who lived in Cyprus. Participants ( 23 were females) were a convenience sample. Most of the participants $(n=25)$ were undergraduate students, majoring in Engineering $(n=6)$, Journalism $(n=5)$, Psychology $(n=$ 4), Primary Education $(n=3)$, Culinary Arts $(n=2)$, Accounting $(n=2)$, Literature $(n=1)$, Interior Design $(n=1)$ and Hospitality and Tourism $(n=1)$. Three of our participants were seniors in high school and 11, who were high school graduates, were working.

\section{Materials}

Epistemic beliefs To assess participants' epistemic beliefs the Livia problem instrument (Iordanou 2016b; Iordanou et al. 2019b; Kuhn et al. 2008; Zavala and Kuhn 2017) was used. The Livia problem presented two contradictory accounts from two historians regarding the fictitious Fifth Livia war, between North and South Livia. One account was from a North Livian historian, and the other was from a South Livian historian. The participants were then asked to answer three questions about their understanding of the discrepancies between the accounts. Participants were asked about the rightness of the accounts (Can one historian be more right than the other?) and the certainty of knowledge (Could anyone ever be certain about what happened in the Fifth Livia war? and What would help us become more certain?) The first two questions received Yes/No responses while the third one was an open-ended question.

History texts Two texts, representing the two opposing perspectives, were used for the thinkaloud procedure. Texts were taken from the History 10th grade textbooks of each of the two ethnic groups. The 'own-side' text was from the Greek-Cypriot history textbook, which is used in the schools of the ethnic group of the participants, whereas the 'other-side' text was from the Turkish-Cypriot history textbook, which is also used in the schools of the other ethnic group. Both texts were biased in favour of a particular ethnic group. For example, the Turkish Cypriot text described the event as a 'peace operation' where Turkey intervene to establish peace in Cyprus, whereas the Greek Cypriot text described the event as an 'invasion' which resulted in many Greek Cypriot refugees.

The text from the other ethnic group was translated in English by a native TurkishCypriot speaker and then to Greek by another researcher. The later translation was back translated to English by an independent researcher to ensure that the meaning has not changed in translations. All the researchers that were involved in the translation of the texts were blind to the objectives of the study. The two texts were of comparable length; the 'ownside' text was 320 words and the 'other-side' text was 309 words. Each sentence was presented in a different flash card, in order to control what the participants read. The order of presentation of the two texts was counterbalanced across participants. Participants were instructed to read aloud each sentence and think aloud. The instructions were the following: "I want you to read the sentence on each card out loud and talk aloud about your thoughts and feelings. Tell me everything that you are thinking - whatever comes to your mind - even if it is not relevant. Think about each sentence carefully, and make sure you understand what you read. Once you have turned to a new card, you will not be allowed to look back at any of 
the previous cards." If the participant did not respond in the first few seconds after reading the sentence aloud, or indicated that s/he was having difficulty talking aloud, the interviewer used the following prompt "What are you thinking or feeling about what you just read?". The texts were presented to participants as extracts from history textbooks. The first sentence in each text included information about the source of the text - Book title, Author, date, pages of the extract.

Prior knowledge To assess participants' prior knowledge participants were asked to answer an open-ended question that asked them to write what they knew about the historical event that was discussed in the history texts.

“Questionnaire emotions” Participants' emotions, particularly' emotions about individuals from the other ethnic group were assessed using a six-item, 5-point Likert Scale questionnaire, from "strongly disagree" to "strongly agree", developed by Zembylas et al. (2011). The questionnaire included statements such as "I dislike Turkish-Cypriots" and "I respect Turkish-Cypriots" (see Table 1).

My-side bias in written report Participants' my-side bias was assessed by asking participants to write a summary of the two controversial historical texts that they read. The instructions were the following "Write a summary of the two texts you just read".

\section{Procedure}

Participants engaged in an individual session, which lasted about one hour. During this session they answered an open-ended question to assess their prior knowledge and the Livia problem (Kuhn et al. 2008) to assess their epistemic beliefs. Participants were then asked to read two conflicting accounts about a controversial issue, in a counterbalanced order, one from a textbook from their own side (Greek-Cypriot side) and the other from a textbook from the other side (Turkish-Cypriot side). Participants' cognitive processing and emotions were evaluated during reading using the think-aloud technique. After reading each sentence in the text, participants were asked to report their thoughts and emotions, which were recorded. Participants' my-side bias in written report was evaluated using a written task that asked participants to write a summary about the two texts. Finally, participants' emotions about the individuals from the adversary ethnic group, were measured using a self-report questionnaire (Zembylas et al. 2011).

Table 1 Questions used to assess participants' emotions towards the other ethnic group

To what degree do the below apply to you personally?

1. I trust Turkish-Cypriots

2. I respect Turkish-Cypriots

3. I consider Turkish-Cypriots to be equal to Greek-Cypriots

4. I avoid Turkish-Cypriots

5. I dislike Turkish-Cypriots

6. I feel sorry for Turkish-Cypriots 


\section{Coding schemes}

Prior knowledge Participants' responses to the open-ended question were coded based on the number of events that participants provided to address the question of reporting on the events that took place in their country during a historical event (1974 war). Participants received a score of 0 if they did not report any event and 1 point for each new event they reported. Random selection of $30 \%$ of students' responses were rescored by an independent rater, resulting in a $95 \%$ agreement. Disagreements were resolved through discussion.

Cognitive strategies employed during reading Participants' think-aloud protocols were transcribed, with 522 mean number of words in the transcribed protocol ( $M=512$ for the own-side text and $M=532$ for the other-side text) and segmented into idea units. Each idea unit was coded for cognitive and meta-cognitive processes during reading, following Kendeou and van den Broek (2007) and Iordanou et al. (2019b) coding schemes, which have been developed following the grounded theory approach (see Table 2). The coding scheme included coherence-based processing, non-coherence based processing, and meta-cognitive processing (which involved meta-comprehension and epistemic processing). Epistemic processing was further coded as either high or low epistemic processing (Iordanou et al. 2019b). Specifically, statements that included a judgment of the content of the text accompanied by a justification based on criteria to support that judgment were coded as high epistemic statements, whereas statements that included judgments without any justification were coded as low epistemic processing statements. The latter case usually manifested as simple disagreement statements (e.g. I disagree with this). Each idea unit received only one code. Inter-rater reliability, based on $30 \%$ of the data, was $90 \%$. Disagreements were resolved through discussion. A research assistant scored the rest of the transcripts.

In addition, participants' emotions during the think-aloud process were recorded. We have reviewed the think-aloud protocols and identified the emotions that participants reported. We noted only emotions that were explicitly expressed by the participants (e.g. I feel sad; I am proud; I am disappointed; I am happy). Table 4 shows all the "think aloud emotions" that were expressed by the participants during reading, for each text.

Epistemic beliefs Each participant's response to the Livia problem was coded using the coding scheme that was developed by Kuhn et al. (2008) and used also by Iordanou et al. (2019b). Participants were classified as holding absolutist epistemic beliefs if they responded that one view could be more right than the other and certainty was empirically possible via direct observation of data or by asking a historian or could be possible if we could overcome some practical limitations (e.g. asking an eyewitness). Participants were classified as holding multiplist epistemic beliefs if they reported that one view could not be more right than the other and certainty was not possible because of the subjective nature of human knowing. Finally, participants were classified as holding evaluativist epistemic beliefs if they reported that one view could be more right than the other and certainty was not possible, but it could be approachable through investigation, analysis and interpretation of evidence. Two coders, blind to the identity of the participants coded all responses. Percentage agreement between the two coders was $89 \%$. Disagreements were resolved through discussion. 
Table 2 Think-aloud coding scheme

Connecting inferences

Reinstatement inferences

Elaborative inferences

Predictive inferences
Coherence-based processing

involve explaining the contents of the current sentence by connecting its meaning with the immediately preceding sentence.

when readers attempt to provide an explanation for the current sentence on the basis of prior text information that was not in the immediately preceding sentence.

when readers attempt to explain the contents of the current sentence on the basis of background knowledge.

anticipating what will occur next in the text. Inconsistent or Invalida:

The statement that the reader just made is not relevant to the text, the
Text:

"In the morning (July 20, 1974) at

5:30 am, the Turkish Armed

Forces landed [in Cyprus] off

Yavuz Cikarma Plaji beach, to restore order, and bring back the peace and rights of the Turkish Cypriots."

Think Aloud:

"It mentions again that the main reason they invaded the island was to protect the Turkish Cypriots who for some reason, after being mistreated as reported by Greek Cypriots..." (reference to information presented in the immediately preceding sentence)

Text: "The casualties amounted to 2850 people, mostly civilians, cold-blooded by the Turkish invaders."

Think aloud:

"This is where the Turkish side itself reveals its intentions, because while appearing in peaceful intentions, there are still thousands who were killed and were civilians. That is, female children and civilians, not just the army."

(reference to prior text "The shipwreck of the Geneva Conference subsequently revealed Turkey's real intentions, which on 14 August 1974 launched a new offensive against Cyprus and completed its expansionist objectives, conquering $36.4 \%$ of the Cypriot territory with weapons.")

Text: "Prime Minister Bulent Ecevit, the "prime minister of the invasion", as he was then known, gave the green light to the Attila hordes, citing the terms of the Guarantee Treaties and the argument for the protection of the Turkish Cypriots.

Think aloud:

"Here it seems that the Turkish army is taking advantage of the provision of the Zurich-London Treaty for immediate intervention and seems to be the right time to intervene on the island. ..."

Text (a sentence that occur after the sentence that the reader just read and was thinking aloud about: "1619 individuals are missing, 
Table 2 (continued)

Associations

Paraphrases

Text repetitions

Belief based statements

\section{Meta-Comprehension: Metacognitive comments on the process of reading comprehension}

Epistemic processing of text content

High Epistemic processing

Low Epistemic processing reader may have a misconception, made a mistake, or may have misread.

Consistent or Valid: The statement the reader just made is somehow relevant to the text.

Non-Coherence based Processing refer to concepts from background knowledge that were brought to mind by the text. Giving examples, visualizations.

when readers put the current sentence or part of the current sentence into their own words.

verbatim reiterations of the current sentences.

Belief-based statements for own side and against other side.

Meta-cognitive Processing

When readers reflect on their understanding with the text.

When readers reflect on their lack of understanding of text information.

When there is a lack of prior knowledge with the text.

When readers evaluate the content of the text, judging the opinion expressed in the text.

The judgment is accompanied with a justification based on criteria (e.g. scientific methodology).

Judgment, usually in the form of disagreement, without any justification. while twenty thousand Greek

Cypriots remained trapped in occupied Cyprus."

Think Aloud:

"There are many (Greek Cypriots) that we don't know what happened to them (after the war).

Think Aloud:

"According to some sources, either valid or invalid, there is evidence that the island was partitioned long before the invasion and (there were) maps and Turkey's main intention was to conquer a part of Cyprus rather than the whole (island) for military bases since it has a very good geographical location."

Text: "The Turkish invasion began on Saturday dawn"

Think Aloud:

"They caught them while they were sleeping."

Text: "At the Nicosia Airport area and elsewhere, despite apparent Turkish arrogance, ELDYK and National Guard forces fought fierce battles against the invaders."

Think Aloud:

"The Greeks, together with the Cypriots, tried to resist the Turks and the Turkish Cypriots in the Nicosia camp."

"I want all the Turks to die."

"I don't know about the subject. I haven't read anywhere..."

"This is not reliable. This is Turkish's points of view."

"I disagree with this."

a There were no cases of Invalid Predictive inferences

My-side Bias Participants' written summaries were coded as two-sided, if they included information from both texts, consistent with the instructions which explicitly asked them to 
provide a summary of both texts, or as one-sided if they included information from only one text. A random selection of $30 \%$ summaries were independently scored by another researcher, resulting in an overall $92 \%$ agreement. Disagreements were resolved through discussion. The first author scored the rest of the participants' summaries.

\section{Results}

\section{Preliminary analysis}

Overall, (Greek-Cypriot; GCs) participants expressed positive emotions towards individuals of the other ethnic group (Turkish-Cypriots; TCs), in their responses in the emotions' questionnaire. With a mean score of $2.71(S D=.86)$ in the likert-point scale with a 5-point range, they showed that they hold relatively positive emotions towards TCs, such as respect and trust.

In contrast, the emotions reported during reading using the think-aloud method were mostly negative (e.g., sad and angry; see Table 4) for both the other-side text and the own-side text. The mean percentage of the emotion of being angry reported was $17 \%(S D=.34)$ when reading the other-side text and $15 \%(S D=.30)$ when reading the own-side text. The mean percentage of the emotion of being sad reported was $17 \%(S D=.36)$ for the other-side text and $24 \%(S D=.34)$ for the own-side text.

Regarding participants' epistemic beliefs, nine of the participants exhibited evaluativist epistemic beliefs, while the remaining 30 participants exhibited either absolutist or multiplist epistemic beliefs (26 were Absolutists, 2 were Multiplists and 2 exhibited a Mix AbsolutistMultiplist profile). Participants' responses in the prior knowledge test ranged from 6 to 28 events, with a mean of $15.03(S D=6.13)$. All the events that participants provided to address the question of what happened in Cyprus in 1974 were consistent with the view shared by their ethnic group, the Greek-Cypriot side. None of the respondents provided an alternative interpretation regarding the event (e.g. the causes of the war).

In the Written Summary, only $28 \%$ of the participants included information from both texts - two-sided report. The majority of the participants, $72 \%$ provided a summary only of the Greek-Cypriot historian's text, which was consistent with their prior knowledge - one-sided report, despite the fact that they had been explicitly instructed to provide a summary of both texts. The participants who included information from both texts reported the two alternative explanations separately as two different interpretations.

Table 3 Proportions (and standard deviations) of coherence, non-coherence and meta-level statements during think-aloud reading of own-side and other-side texts

\begin{tabular}{llllll}
\hline & $\begin{array}{l}\text { Coherence- } \\
\text { based }\end{array}$ & $\begin{array}{l}\text { Non- } \\
\text { Coherence } \\
\text { based }\end{array}$ & $\begin{array}{l}\text { Meta-level statements: } \\
\text { Meta-Comprehension }\end{array}$ & $\begin{array}{l}\text { Meta-level statements: Low } \\
\text { epistemic processing }\end{array}$ & $\begin{array}{l}\text { No } \\
\text { statement }\end{array}$ \\
\hline $\begin{array}{c}\text { Other-Side } \\
\text { Text } \\
\text { Own-side } \\
\text { text }\end{array}$ & $.55(.20)$ & $.15(.13)$ & $.08(.12)$ & $.22(.16)$ & $.02(.07)$ \\
\hline
\end{tabular}




\section{Cognitive processing of own-side text and other-side text}

To examine to what extent individuals differentially process own-sided and the other-sided accounts (Research Question 1), a repeated measures MANOVA was performed on four dependent variables (DVs): Coherence, non-coherence, meta-comprehension and epistemic statements reported during think-aloud when reading each text (Table 3). With the Pillai's Trace criterion, the combined DVs were significantly affected by the text type, $F(4,34)=$ 18.404, $p<.001$, partial $\eta^{2}=.684$. There were significant text type differences in epistemic processing, $F(1,37)=54.471, p<.001$, partial $\eta^{2}=.596$. Although a quarter of the statements reported when reading the other-side text were low epistemic statements, $M=.22(S D=.16)$, when reading the own-side text participants engaged in almost no epistemic processing, $M=.003(S D=.02)$. Significant text type differences were also observed in the meta-comprehension processing, $F(1,37)=11.738, p=.002$, partial $\eta^{2}=.241$. As was the case with epistemic processing, participants engaged in more meta-comprehension processing when reading the other-side text, $M=.08(S E=.12)$, than when reading the own-side text, $M=.01$ $(S D=.03)$. Finally, significant text type differences were observed in coherence statements, $F(1,37)=35.026, p<.001$, partial $\eta^{2}=.486$. Participants engaged in less coherence-based processing when reading the own-side text, $M=.55(S D=.20)$, than when reading the otherside text $M=.71(S D=.19)$. There were no significant text differences for non-coherence statements, $F(1,37)=1.659, p=.206$, partial $\eta^{2}=.043$.

\section{Epistemic beliefs, prior knowledge and "think aloud" emotions as predictors of cognitive processing}

For "think aloud" emotions, we evaluated overall prevalence (Table 4) and used in subsequent analyses the most prevalent emotions reported - anger and sadness $(M>.15)$. Bivariate correlations between epistemic beliefs, prior knowledge, "think aloud" emotions, coherencebased, non-coherence-based, meta comprehension and epistemic processing during reading of the own-side text and the other-side text are presented in Table 5.

As seen in Table 5, the analysis showed a relation between epistemic processing of the otherside text with epistemic beliefs, prior knowledge and the "think aloud" emotion of anger. A relation was also observed between coherence-based processing of the other-side text, the "think aloud" emotion of sadness and prior-knowledge. To examine to what extent epistemic beliefs, prior knowledge and "think aloud" emotions predict cognitive processing when reading historical accounts about a controversial topic (Research Question 2), we investigated further, with multiple regression analysis, the relationships that were observed in the correlational analysis.

A standard multiple regression was performed between epistemic processing during other-side text as the dependent variable and epistemic beliefs, prior knowledge, and the "think aloud emotion" of anger as independent variables. Table 6 displays the correlations between the variables, the unstandardized regression coefficients $(b)$ and intercept, the standardized regression coefficients $(\beta)$, $R^{2}$ and adjusted $R^{2}$. R for regression was significantly different from zero, $F(3,31)=5.934, p=.003$, with $R^{2}$ at .37 with a $95 \%$ confidence interval ranging from 0.140 to 0.589 . The adjusted $R^{2}$ value of .30 indicates that a third of the variability in epistemic processing is predicted by epistemic perspective, the "think aloud" emotion of anger and prior knowledge. The size and direction of the relationships suggests that more epistemic processing was exhibited by individuals with evaluativist epistemic perspective and those expressing more anger during reading. 







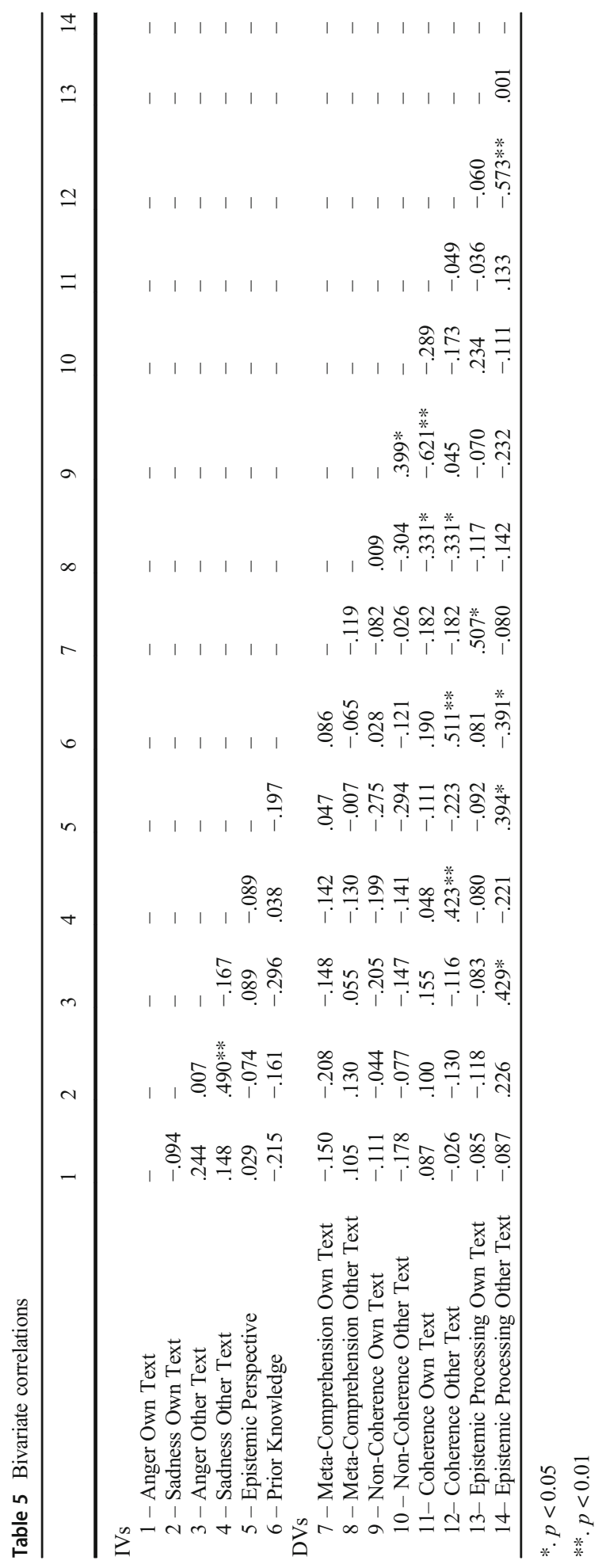


Table 6 Multiple regression of epistemic perspective, "think aloud" emotion of anger and prior knowledge on epistemic processing of the other side text

\begin{tabular}{llll}
\hline & $b$ & $S E(b)$ & $\beta$ \\
\hline Epistemic perspective & $.123^{*}$ & .055 & .321 \\
Anger & $.152^{*}$ & .070 & .325 \\
Prior knowledge & -.007 & .004 & -.253 \\
& & & $R^{2}=.37$ \\
& & & Adjusted $R^{2}=.30$ \\
& & & $R=.60$ \\
\hline
\end{tabular}

$* p<.05$

A standard multiple regression was also performed with coherence-based processing during reading of other-side text as the dependent variable and the "think aloud" emotion of sadness and prior-knowledge as the independent variables. $\mathrm{R}$ for regression was significantly different from zero, $F(2,37)=12.902, p<.001$, with $R^{2}$ at .424 with a $95 \%$ confidence interval ranging from 0.205 to 0.643 . The adjusted $R^{2}$ value of .391 indicates that $39 \%$ of the variability in coherence-based processing was predicted by the "think aloud" emotion of sadness and priorknowledge. Both the "think aloud" emotion of sadness and prior knowledge, as seen in Table 7, were significant predictors in the model. The direction of the relationship suggests that more coherence-based processing was exhibited by individuals who expressed more sadness during reading and had more prior-knowledge.

\section{Epistemic beliefs and my-side bias in written summary reports}

To examine whether epistemic beliefs related to my-side bias in the written summaries (Research Question 3), we conducted a chi-square test of independence. In particular, we examined whether individuals' epistemic perspective (Evaluativists, Non-Evaluativists) and my-side bias (one-sided report vs. two-sided report) were independent of one another. A chi-square test of independence showed a significant relation $\left(\chi^{2}(1)=4.508,4.059, p=.044\right)$. Participants holding evaluativist epistemic beliefs were more likely to write two-sided reports than participants holding absolutist or multiplist epistemic beliefs. In other words, participants with less mature epistemic beliefs - holding either absolutist or multiplist epistemic beliefs - were more likely to exhibit my-side bias in their written reports, writing a summary of only the text of the historian from their ethnic group, than participants with more mature, evaluativist, epistemic beliefs.

Table 7 Multiple regression of prior knowledge and "think aloud" emotion of sadness on coherence-based processing of the other side text

\begin{tabular}{llll}
\hline & $b$ & $S E(b)$ & $\beta$ \\
\hline Sadness & $.258^{*}$ & .082 & .405 \\
Prior Knowledge & $.019^{* *}$ & .005 & .495 \\
& & & $R^{2}=.42$ \\
& & & Adjusted $R^{2}=.39$ \\
& & & $R=.65$ \\
\hline
\end{tabular}

$* p<.05$

$* * p<.001$ 


\section{Discussion}

The objectives of the present study were to examine individuals' thinking when reading controversial historical accounts and the possible contribution of epistemic beliefs, emotions and prior-knowledge. In addition, we aimed to examine if there was a relationship between epistemic beliefs and my-side bias in the summary reports participants constructed after reading two controversial accounts.

Starting with our first research question, namely whether individuals' cognitive processing differed when reading an own-side account which was consistent with their beliefs - from a historian of their ethnic group, Greek-Cypriot historian - versus an other-side account which was not consistent with their beliefs - from a historian from another ethnic group, TurkishCypriot historian - on a controversial issue, our findings suggest an affirmative answer. Participants engaged in coherence-based processing, but they did not engage in any kind of reflective thinking when they were reading the own-side account. In contrast, participants engaged in meta-comprehension and low epistemic processing, mainly by stating their disagreement, when they were reading the other-side account. When asked to write a summary of the two accounts, the majority of the participants reported only their own-side position, from the own-side text, while only one third of them made reference to both texts - own-side and other-side texts -, writing two-sided repots and showing less my-side bias. In an effort to gain an understanding of the factors that might have contributed to writing a two-sided report by some participants (our third research question), additional analyses highlighted the role of epistemic beliefs. Our findings regarding the factors that affected cognitive processing (our second research question) during reading highlighted the role of epistemic beliefs and the "think aloud" emotions of anger and sadness. Epistemic beliefs, along with prior knowledge and the "think aloud" emotion of anger expressed during reading, explained engagement in low-level meta-level processing, while the "think aloud" emotion of sadness and prior knowledge explained engagement in coherence-based processing during reading of the other-side text. Our results show that text processing during reading is a complex process, which involves the interplay of different factors, such as emotions, epistemic beliefs, prior knowledge, and biases; these factors affect text processing and ultimately learning from texts. The present study contributes to the literature in several respects which are discussed below.

Overall, the findings of the present study are in line with the cognitive and motivation biases reported in the reasoning literature. Bias was observed both in argument production - as it was evident in participants' responses in the prior knowledge test and the summary reports - and in argument evaluation, during reading - as it was revealed by the think-aloud methodology. The findings of the cognitive processing of information during reading are consistent with the disconfirmation bias (Edwards and Smith 1996) and other empirical findings showing that individuals tend to engage in superficial processing of belief-consistent information, without engaging in critical evaluation of the information, while they tend to examine belief-inconsistent information to a greater extent and try to refute them (Maier et al. 2018a; McCrudden and Sparks 2014; Pronin et al. 2002; Voss et al. 1993). The finding that participants did not engage in any kind of evaluative examination when reading the position that was consistent with their prior beliefs is also consistent with my-side bias (Baron 1995). This is also in line with findings of previous research showing biases in individuals' reasoning in history, in favour of their own ethnic group (Goldberg and Schwarz 2016; Putnam et al. 2018; Zaromb et al. 2018). Notably in the written task, even though participants were explicitly asked to write a summary about the two texts they read - own- and other-side texts - 
the majority of the participants based their reports only on one text, the own-side text which was consistent with their beliefs.

This finding can be explained by a belief protection mechanism, according to which individuals purposefully ignore belief-inconsistent arguments that might challenge their prior beliefs (McCrudden and Sparks 2014). Another possible explanation might be that most individuals fail to take into consideration multiple perspectives at the same time (Wansink et al. 2018). In particular, they do not conceptualize multiple contributing causes as necessary to account for most phenomena, nor are they likely to take multiple considerations into account in making judgments of a non-causal nature (Kuhn and Iordanou in press).

Evaluating claims against one's prior knowledge, especially if one's beliefs are aligned with the views of the international community and international law, does not necessarily imply biased thinking. However, one would expect to see evidence of reflective thinking when processing historical accounts. For example, participants could have reflected on the fact that the own-side account presented losses of their ethnic group only (e.g. refugees), however none of them did. In the writing task, one would expect participants to be able to provide a summary of the other-side report, even though they disagree with this view. The majority of the individuals, however, totally ignored the other side account, even though they were clearly asked to summarize the two texts. It is the omission of the 'other' perspective which we conceive as evidence of bias. Given that the behaviour exhibited was consistent among participants (i.e. those who wrote one-sided reports, all included a summary of their own side account only, with none of them including a summary of the other-side account, and disapproval comments were only expressed when reading the other-side account), it is likely that the roots of participants' beliefs lie at the cultural level. The behaviour observed in the current study is consistent with the mechanism of naïve realism from cultural cognition, according to which individuals show the disposition to view their own cultural group's beliefs as the product of "objective" assessment and the adversary cultural group's beliefs as the product of bias (Kahan and Braman 2006). Ignoring other's side view on a controversial historical event, as was observed in present study, is a matter of concern in an ethnically divided society which seeks to promote peace in the society (Zembylas 2015).

Yet, our findings demonstrate that epistemic beliefs can mitigate, to some degree, the tendency to dismiss belief-inconsistent information as it was evident more clearly in the writing task, where individuals with evaluativist epistemic beliefs were more likely to include information both from the own-side and other-side texts than individuals with a multiplist or an absolutist epistemic beliefs. This finding provides further support to theories which support that epistemic beliefs support reasoning (Kuhn, 1991; Iordanou 2016b) and particularly the reconciliation of contradictory exploratory accounts about complex issues (Kuhn 2019). Our finding, highlighting the role of epistemic beliefs in writing two-sided reports, is consistent with previous empirical findings (Mason and Scirica 2006; Baytelman et al. 2020; Iordanou 2016b). Yet, the present study extends the literature by showing firstly that advanced epistemic beliefs are related with two-sided thinking not only in the context of neutral, usually scientific issues, but also in an emotionally-charged controversial historical issue, where individuals are more likely to exhibit biases. Secondly, a point which is relevant to the point made earlier but worth mentioning, is that individuals with evaluativist epistemic beliefs incorporated information not only from multiple "neutral" texts, but they did so with a text which included information that was not consistent with their initial beliefs on the issue.

The interpretation of our findings regarding the cognitive processing that took place during reading of the other-side text is not straightforward. Participants engaged to some extent to 
evaluation of the information when reading the other-side account, yet this evaluation was of low-quality, in the form of expression of unjustified disagreement. The epistemic processing was most likely to take place among participants who hold evaluativist epistemic beliefs, low prior-knowledge and those who reported that were angry while reading. We discuss next the contribution of each one of these variables in cognitive processing of information.

The relation between epistemic processing during reading and epistemic beliefs is consistent with previous findings showing that epistemic beliefs predict thinking in neutral topics (Iordanou et al. 2019b). Comparing though our findings with the findings of other studies employed similar methodology (e.g. Iordanou et al. 2019b) - where even younger participants engaged in better reflective thinking - we infer that participants' emotional investment on the topic in the present study might have impeded the cognitive processing that they engaged in, suggesting that high negative affect on a topic is not related with better thinking (Edwards and Smith 1996; Fisher and Keil 2014; Kuhn and Iordanou in press; Maier et al. 2018a; Mason et al. 2018). This interpretation is in line with the Cognitive Affective Engagement Model's "affectively engaged default stance" (List and Alexander 2017), which refers to students who exhibit strong affective engagement but not the skills necessary to engage in evaluation and integration of information when approaching multiple text tasks. The present study shows that the emotion of anger was related to superficial cognitive processing during reading of multiple texts. A more positive interpretation of this finding is that engagement in some evaluative activity, even of a low quality - of just expressing a simple disagreement judgment, rather than providing justifications based on criteria - might be an antecedent of a more skilful evaluation ability. Recent models of epistemic cognition (Barzilai and Chinn 2018; Iordanou 2016a) proposed that the evaluation skill and the standards of evaluation follow a developmental progression. Only future research can answer the question of whether individuals, more likely individuals with evaluativist epistemic beliefs, who showed low epistemic processing in reading controversial historical accounts can develop their evaluation skills, and under which conditions.

Regarding the role of emotions in cognitive processing, the results suggest that the affective component should be taken into account when examining multiple source processing, as proposed in the Cognitive and Affective Engagement Model (List and Alexander 2017). For interpreting the relation observed between anger, in particular, and low epistemic processing, there are competing explanations depending on how low-epistemic processing is viewed. One explanation is that anger had motivated participants to engage in some type of evaluation, even of a low quality. According to Bendixen (2010) emotional engagement, including political anger, is a requirement for reasoning in socio-political issues. An alternative explanation is that anger impeded short-term high level cognitive processing. The relation observed between anger and low-level epistemic processing, particularly in the form of expressing disagreement, might suggest that angry subjects were more prone to biases. The disagreements exhibited can be interpreted as a tendency to refute the belief-inconsistent information according to the disconfirmation bias (Edwards and Smith 1996) in order to protect their beliefs (Maier et al. 2018a; McCrudden and Sparks 2014; Pronin et al. 2002; Voss et al., 1993).

Noteworthy this tendency for disconfirmation of belief inconsistent information was more likely to take place when the emotion of anger was reported but not when the emotion of sadness was reported. In contrast, the emotion of sadness, which is a more passive emotion compared to anger, predicted coherence-based processing, but not advanced reflective processing. This finding is consistent with the findings of Bodenhausen et al. (1994) who found that anger had very different effects from sadness in evaluations of social information. In that study anger, but not sadness, was related with greater reliance on heuristic cues in social judgment. Anger, which is associated with 
increased activation in the cerebral activity (Foster and Harrison 2002), might be more disruptive to cognitive processing than sadness. It remains for future research to delineate the relation between emotion and cognitive processing in historical controversial issues, getting a richer understanding of both the cognitive processing and the emotions that individuals experience when dealing with historical controversial topics. For example, retrospective interviews can be used to get a better understanding of the nature of the disagreements that were exhibited during cognitive processing i.e. was it a simple disapproval of the opposing position or some developing evaluation ability? Similarly, future research can analyse deeper the emotions that were reported, examining for example what has triggered a particular emotion - i.e. Has the anger been triggered by the content of the message or the messenger (e.g. being an out-of-group member)? Nevertheless, our findings have important implications for future research examining the relation between emotion and cognition. Our finding that participants' momentary emotions, expressed during reading using the think-aloud methodology, differed from the topic emotions that they self-reported in a paper-andpencil instrument after reading, but the former predicted the cognitive processing that individuals engaged in during reading, suggests that future research should pay closer attention to momentary emotions.

Finally, the relation between prior knowledge and coherence-based processing is consistent with evidence in previous research (Bohn-Gettler and Kendeou 2014). Prior knowledge enables participants to integrate text information and generate inferences in an effort to build a coherent situation model during reading (Kendeou and O'Brien 2016). In this context, knowledge about the historical events described in the texts was particularly important in helping participants negotiate the reading task effectively and engage in coherence-building processes. These processes manifested as connecting, reinstating, elaborative, and predictive inferences.

Some limitations of the present study that need to be considered is the sample size and the fact that the participants of the study were volunteers. Without random sampling, the possibility of self-selection bias remains a threat. Further research is recommended for replicating our findings, using a representative sample, and for getting a fuller understanding of text processing of controversial historical issues and the factors that affect this processing.

The findings from this study have nevertheless important educational implications. There is a general consensus that the development of evaluative skills should be a top priority for education, especially for citizenship education (Bendixen 2010), but also for social studies and history (Bermudez 2015). The findings of the present study, showing a relation between advanced epistemic beliefs and the ability to construct a two-sided report on a controversial topic, suggest that investing in promoting individuals' epistemic cognition might be a promising pathway for reducing my-side bias when thinking about a controversial historical issue. Educators should invest in efforts aiming to promote students' epistemic cognition, such as engaging students in dialogic activities on controversial issues which research shows to be promising for promoting students' epistemic cognition (Iordanou 2016b).

For considering multiple perspectives on a historical issue it is important for the individuals to be exposed to different views and multiple interpretations of a historical event. Although none of our participants considered an alternative interpretation of the historical event before reading the texts, after reading an authentic text giving an alternative perspective, from an out of group historian, some participants did include this alternative perspective of the historical event that they read in the reports that they wrote. This finding is in line with recent research findings showing that individuals' learning and reasoning in history was improved after direct or indirect engagement with alternative interpretations (De La Paz and Felton 2010; Goldberg et al. 2011). For example individuals showed improvements in their reasoning skills after reading different sources and engaging in scaffolding 
activities (De La Paz and Felton 2010), group discussion (Goldberg et al. 2011) or reading a refutation text, which addressed and refuted individuals' misconceptions explicitly based on factual information rather on bias (Donovan et al. 2018). A recent study comparing direct with indirect engagement with alternative views for a physical science topic showed that direct engagement, in the form of discussing with individuals who genuinely support an opposing view, is more fruitful for promoting individuals' reasoning skills than indirect engagement - reading and discussing an alternative view with peers who do not support an opposing view from one's own view (Iordanou and Kuhn 2020). Of course, further research is required to explore the effects of direct engagement in controversial historical issues. Nevertheless, our findings confirm that it is important in teaching a historical issue to use multiple sources which approach an issue from different, even controversial, perspectives (Nordgren and Johansson 2015; Stradling 2003; Wansink et al. 2018).

Finally, the biases and limitations exhibited in individuals' thinking, particularly the absence of deep reflective thinking on a historical controversial issue which has consequences on individuals' development and the future of their country is a matter of concern. Development occurs in the ability to comprehend and reflect on belief-inconsistent but also belief-consistent views (Moshman 2005). The limitations exhibited in individuals' historical thinking in particular, suggest that psychologists and educators need to pay closer attention on critical thinking on historical controversies. Future research needs to explore ways of supporting individuals' critical thinking skills on controversial emotionally-charged historical open issues of "real" life. Previous research showed that by engaging young adolescents over an extended period in discussions with peers holding opposing positions can be beneficial for supporting the development of young adolescents two-sided thinking on the issue (Iordanou et al. 2019a; Iordanou and Kuhn 2020). Whether a comparable result is achievable in examining issues in which they may have considerable affective investment, such as controversial historical issues, is a well worth investigating question.

Open Access This article is licensed under a Creative Commons Attribution 4.0 International License, which permits use, sharing, adaptation, distribution and reproduction in any medium or format, as long as you give appropriate credit to the original author(s) and the source, provide a link to the Creative Commons licence, and indicate if changes were made. The images or other third party material in this article are included in the article's Creative Commons licence, unless indicated otherwise in a credit line to the material. If material is not included in the article's Creative Commons licence and your intended use is not permitted by statutory regulation or exceeds the permitted use, you will need to obtain permission directly from the copyright holder. To view a copy of this licence, visit http://creativecommons.org/licenses/by/4.0/.

\section{References}

Baron, J. (1995). Myside bias in thinking about abortion. Thinking and Reasoning, 1, 221-235.

Baron, J. (2019). Actively open-minded thinking in politics. Cognition, 188, 8-18.

Barzilai, S., \& Chinn, C. A. (2018). On the goals of epistemic education: Promoting apt epistemic performance. Journal of the Learning Sciences, 27(3), 353-389.

Baytelman, A., Iordanou, K., \& Constantinou, C. P. (2020). Epistemic beliefs and prior knowledge as predictors of the construction of different types of arguments on socioscientific issues. Journal of Research in Science Teaching, 57(8), 1199-1227. https://doi.org/10.1002/tea.21627.

Bendixen, L. D. (2010). Argumentation, anger, and action: Citizenship education in and out of the classroom. Journal of Peace Education and Social Justice, 4(1), 108-119.

Bermudez, A. (2015). Four tools for critical inquiry in history, social studies, and civic education. Revista de Estudios Sociales, 52, 102-118.

Bodenhausen, G. V., Sheppard, L. A., \& Kramer, G. P. (1994). Negative affect and social judgment: The differential impact of anger and sadness. European Journal of Social Psychology, 24(1), 45-62. 
Bohn-Gettler, C. M., \& Kendeou, P. (2014). The interplay of reader goals, working memory, and text structure during reading. Contemporary Educational Psychology, 39, 206-219.

Burbridge, J. A., Larsen, R. J., \& Barch, D. M. (2005). Affective reactivity in language: The role of psychophysiological arousal. Emotion, 5(2), 145-153.

D’Mello, S., Lehman, B., Pekrun, R., \& Graesser, A. (2014). Confusion can be beneficial for learning. Learning and Instruction, 29, 153-170.

De La Paz, S., \& Felton, M. K. (2010). Reading and writing from multiple source documents in history: Effects of strategy instruction with low to average high school writers. Contemporary Educational Psychology, 35(3), 174-192.

Diakidoy, I. A. N., Christodoulou, S. A., Floros, G., Iordanou, K., \& Kargopoulos, P. V. (2015). Forming a belief: The contribution of comprehension to the evaluation and persuasive impact of argumentative text. British Journal of Educational Psychology, 85(3), 300-315.

Donovan, A. M., Zhan, J., \& Rapp, D. N. (2018). Supporting historical understandings with refutation texts. Contemporary Educational Psychology, 54, 1-11.

Edwards, K., \& Smith, E. E. (1996). A disconfirmation bias in the evaluation of arguments. Journal of Personality and Social Psychology, 71(1), 5-24.

Engle, R. W. (2018). Editor's introduction: Special issue on racism. Current Directions in Psychological Science., 27(3), 147-147.

Fisher, M., \& Keil, F. C. (2014). The illusion of argument justification. Journal of Experimental Psychology: General, 143(1), 425-433.

Foster, P. S., \& Harrison, D. W. (2002). The relationship between magnitude of cerebral activation and intensity of emotional arousal. International Journal of Neuroscience, 112(12), 1463-1477.

Goldberg, T., \& Schwarz, B. B. (2016). Harnessing emotions to deliberative argumentation in classroom discussions on historical issues in multi-cultural contexts. Frontline Learning Research, 4(4), 7-19.

Goldberg, T., Schwarz, B. B., \& Porat, D. (2011). "Could they do it differently?": Narrative and argumentative changes in students' writing following discussion of "hot" historical issues. Cognition and Instruction, 29(2), $185-217$.

Greene, J. A., Sandoval, W. A., \& Bråten, I. (Eds.). (2016). Handbook of epistemic cognition. Routledge.

Ioannou, K., \& Iordanou, K. (2019). Elementary school students' epistemic perspective and learning strategies in history. Learning: Research and Practice. https://doi.org/10.1080/23735082.2019.1591492.

Iordanou, K. (2016a). From theory of mind to epistemic cognition. A lifespan perspective. Frontline Learning Research, 4(5), 106-119.

Iordanou, K. (2016b). Developing epistemological understanding through argumentation in scientific and social domains. Zeitschrift für Pädagogische Psychologie., 30(2-3), 109-119.

Iordanou, K., \& Kuhn, D. (2020). Contemplating the opposition: Does a personal touch matter? Discourse Processes, 57(4), 343-359.

Iordanou, K., Kuhn, D., Matos, F., Shi, Y., \& Hemberger, L. (2019a). Learning by arguing. Learning and Instruction, 63, 101-207.

Iordanou, K., Muis, K., \& Kendeou, P. (2019b). Epistemological understanding, prior-knowledge and meta-level processing of evidence during reading in young adolescents and adults. Journal of Experimental Education, 87(4), 531-551.

Kahan, D. M., \& Braman, D. (2006). Cultural cognition and public policy. Yale L. \& Pol'y Rev., $24,149$.

Kendeou, P., \& O'Brien, E. J. (2016). Prior knowledge: Acquisition and revision. In P. Afflerbach (Ed.), Handbook of individual differences in Reading: Reader, text, and context (pp. 151-163). New York: Routledge.

Kendeou, P., \& van den Broek, P. (2007). The effects of prior knowledge and text structure on comprehension processes during reading of scientific texts. Memory \& Cognition, 35(7), 1567-1577.

Kuhn, D. (1991). The skills of argument. Cambridge University Press. https://doi.org/10.1017 /CBO9780511571350.

Kuhn, D. (2001). How do people know?. Psychological science, 12(1), 1-8.

Kuhn, D. (2019). Why is reconciling divergent views a challenge? Current Directions in Psychological Science, 29(1), 27-32.

Kuhn, D., \& Iordanou, K. (in press). Why do people argue past one another rather than with one another? In N. Ballantyne \& D. Dunning (Eds.), Reason, bias, and inquiry: New perspectives from the crossroads of epistemology and psychology. New York: Oxford University Press.

Kuhn, D., Cheney, R., \& Weinstock, M. (2000). The development of epistemological understanding. Cognitive Development, 15(3), 309-328.

Kuhn, D., Iordanou, K., Pease, M., \& Wirkala, C. (2008). Beyond control of variables: What needs to develop to achieve skilled scientific thinking? Cognitive Development, 23, 435-451. 
Kuhn, D., Hemberger, L., \& Khait, V. (2016). Tracing the development of argumentive writing in a discourserich context. Written Communication, 33(1), 92-121.

List, A., \& Alexander, P. A. (2017). Cognitive affective engagement model of multiple source use. Educational Psychologist, 52, 182-199.

Maier, J., \& Richter, T. (2014). Fostering multiple text comprehension: How metacognitive strategies and motivation moderate the text-belief consistency effect. Metacognition \& Learning, 9, 54-71.

Maier, J., Richter, T., \& Britt, M. A. (2018a). Cognitive processes underlying the text-belief consistency effect: An eye-movement study. Applied Cognitive Psychology, 32(2), 171-185.

Maier, J., Richter, T., Nauroth, P., \& Gollwitzer, M. (2018b). For me or for them: How in-group identification and beliefs influence the comprehension of controversial texts. Journal of Research in Reading., 41(1), 4865.

Mason, L., \& Scirica, F. (2006). Prediction of students' argumentation skills about controversial topics by epistemological understanding. Learning and Instruction, 16(5), 492-509.

Mason, L., Scrimin, S., Zaccoletti, S., Tornatora, M. C., \& Goetz, T. (2018). Webpage reading: Psychophysiological correlates of emotional arousal and regulation predict multiple-text comprehension. Computers in Human Behavior, 87, 317-326.

McCrudden, M. T., \& Sparks, P. C. (2014). Exploring the effect of task instructions on topic beliefs and topic belief justifications: A mixed methods study. Contemporary Educational Psychology, 39, 1-11.

Moshman, D. (2005). Adolescent psychological development: Rationality, morality, and identity. Psychology Press.

Muis, K. R., Chevrier, M., \& Singh, C. A. (2018). The role of epistemic emotions in personal epistemology and self-regulated learning. Educational Psychologist, 53(3), 1-20.

Murphy, P. K., \& Alexander, P. A. (2013). Situating text, talk, and transfer in conceptual change: Concluding thoughts. In S. Vosniadou (Ed.), International handbook of research on conceptual change (2nd ed., pp. 603-621). New York: Routledge.

Murphy, P. K., \& Alexander, P. A. (2016). Interrogating the relation between conceptual change and epistemic beliefs. Handbook of Epistemic Cognition, 439-459.

Murphy, P. K., \& Mason, L. (2006). Changing knowledge and beliefs. Handbook of Educational Psychology, 2, 305-324.

Nordgren, K., \& Johansson, M. (2015). Intercultural historical learning: A conceptual framework. Journal of Curriculum Studies, 47, 1-25.

Papadakis, Y. (2008). Narrative, memory and history education in divided Cyprus: A comparison of schoolbooks on the 'history of Cyprus'. History \& Memory, 20(2), 128-148.

Pronin, E., Lin, D. Y., \& Ross, L. (2002). The bias blind spot: Perceptions of bias in self versus others. Personality and Social Psychology Bulletin., 28(3), 369-381.

Putnam, A. L., Ross, M. Q., Soter, L. K., \& Roediger III, H. L. (2018). Collective narcissism: Americans exaggerate the role of their home state in appraising US history. Psychological Science, 29(9), 1414-1422.

Stanovich, K. E., \& Stanovich, P. J. (2010). A framework for critical thinking, rational thinking, and intelligence. Innovations in Educational Psychology: Perspectives on Learning, Teaching and Human Development, 195-237.

Stanovich, K. E., \& West, R. F. (2008). On the failure of cognitive ability to predict myside and one-sided thinking biases. Thinking \& Reasoning, 14(2), 129-167.

Stradling, R. (2003). Multiperspectivity in history teaching: A guide for teachers. Strasbourg, France: Council of Europe.

VanSledright, B., \& Maggioni, L. (2016). Epistemic cognition in history. Handbook of Epistemic Cognition, $128-146$.

Voss, J. F., Fincher-Kiefer, R., Wiley, J., \& Silfies, L. N. (1993). On the processing of arguments. Argumentation, 7, 165-181.

Walton, D. N. (1989). Dialogue theory for critical thinking. Argumentation, 3, 169-184.

Wansink, B., Akkerman, S., Zuiker, I., \& Wubbels, T. (2018). Where does teaching multiperspectivity in history education begin and end? An analysis of the uses of temporality. Theory \& Research in Social Education, 46(4), 495-527.

Wineburg, S. S. (1991). On the reading of historical texts: Notes on the breach between school and academy. American Educational Research Journal, 28(3), 495-519.

Zaromb, F. M., Liu, J. H., Páez, D., Hanke, K., Putnam, A. L., \& Roediger III, H. L. (2018). We made history: Citizens of 35 countries overestimate their Nation's role in world history. Journal of Applied Research in Memory and Cognition, 7(4), 521-528.

Zavala, J., \& Kuhn, D. (2017). Solitary discourse is a productive activity. Psychological Science, 28(5), 578-586.

Zembylas, M. (2015). Emotion and traumatic conflict: Re-claiming healing in education. Oxford: Oxford University Press. 
Zembylas, M., \& Kambani, F. (2012). The teaching of controversial issues during elementary-level history instruction: Greek-Cypriot teachers' perceptions and emotions. Theory \& Research in Social Education, 40(2), 107-133.

Zembylas, M., Charalambous, C., Charalambous, P., \& Kendeou, P. (2011). Promoting peaceful coexistence in conflict-ridden Cyprus: Teachers' difficulties and emotions towards a new policy initiative. Teaching and Teacher Education, 27(2), 332-341.

Zembylas, M., Charalambous, C., \& Charalambous, P. (2016). Peace education in a conflict-troubled society: An ethnographic journey. Cambridge: Cambridge University Press.

Publisher's note Springer Nature remains neutral with regard to jurisdictional claims in published maps and institutional affiliations. 